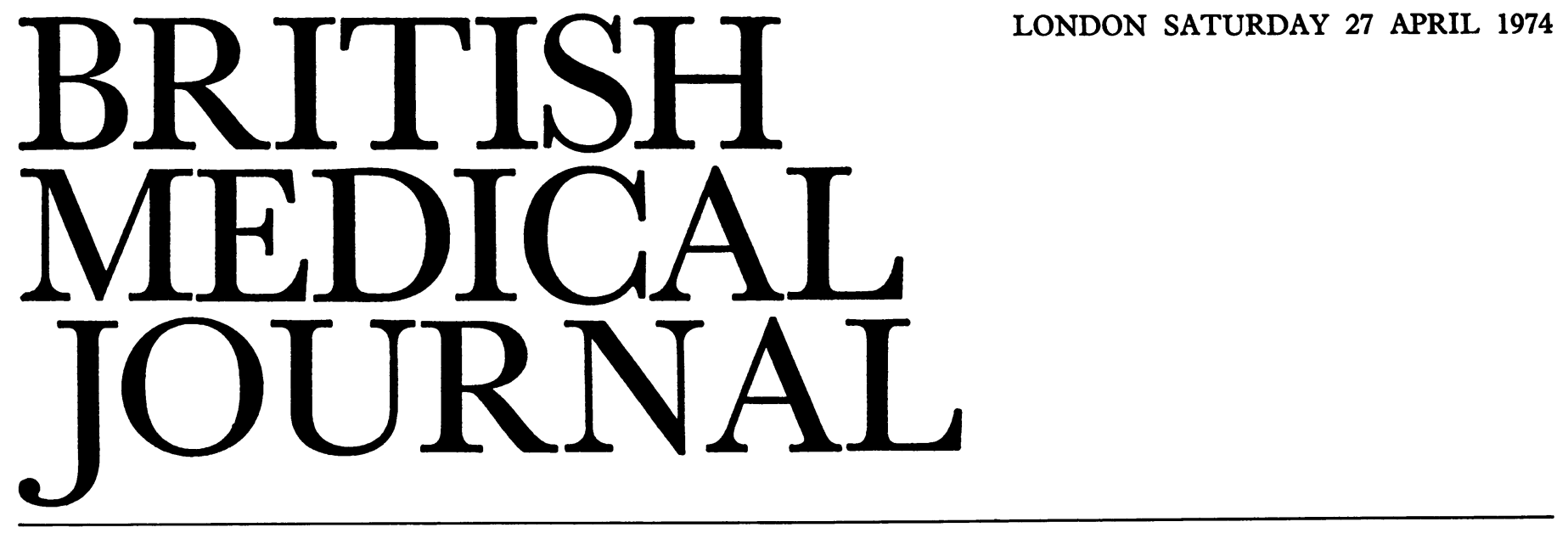

\title{
Both Sides of the Fence
}

Primary scientific journals exist to advance science and scholarship, and their quality largely depends on the standard of their original articles. In its turn the level of these depends on the expert referees who help their editors in assessing individual articles for publication. Most editors seem to believe that this refereeing system works well, yet recently some scientists have questioned whether this assumption is always justified. Obviously the system depends on the referee's honourable behaviour, a presumption which Jones ${ }^{1}$ has stated is no longer true, claiming that "justice can be secured only by altering the system." In this week's B.M.F. (p. 216), also, Dr. D. F. Horrobin has launched a provocative attack on what he terms "the closed system" of allocating research grants and refereeing journal articles, suggesting that this is a real bar to progress. So it is timely to examine the privileges, responsibilities, and expectations of the three sides of the triangle: author, referee, and authority (editor or grant-giving body).

Various agencies differ in their criteria for making a decision. Thus in a journal the referee's opinion is only one of several factors in the editor's final decision. Sometimes, for example, a paper of borderline scientific merit may be written so badly that that is enough to tip the balance against it. Competition for research funds may be such that the projects are placed in order of priority, and below a certain point some have to be rejected merely because money is no longer available.

Both authors of articles and applicants for grants are entitled to expect the same response: prompt and courteous treatment of their article or application-and since most editors and expert referees are authors themselves and have depended on research grants at some time they are likely to get it. Moreover, an author or applicant may reasonably ask on what grounds his article has been turned down or a grant refused and he is entitled to an honest yet kind reply. He may also ask the editor or official body to reconsider the article or application, with his riposte to any referee's report in mind, or to seek further assessment from another expert. But in the end acceptance for publication is a privilege, not a right. In the long run it is the journal that suffers from turning down good work.

The referee's responsibilities were well defined in some guidelines laid down two years ago, though these have not gained the wide publicity they deserved. ${ }^{2}$ Emphasizing that any unpublished manuscript is a privileged document, these guidelines point out the need to protect it from exploitation; to judge it impartially and expeditiously; and to document any criticisms, arguments, and suggestions. Aspects of the article to be considered should include importance of the topic considered; originality of the work and the appropriateness of its design; soundness of the conclusions and relevance of the discussion; and soundness of organization of the paper. The reviewer is asked consciously to adopt a positive, impartial attitude to the manuscript and, in giving any comments intended for the author's eye, to present them dispassionately, avoiding abusive remarks. Finally, the guidelines emphasize another fundamental principle of assessing: "A reviewer's recommendations are gratefully received by the editor, but since editorial decisions are usually based on evaluations derived from several sources, a reviewer should not expect the editor to honour his every recommendation."

In all this the editor's role is to see that the best interests of his subject, profession, or science are served. His job is to preserve standards, being fair to both author and referee, preferably with a slight bias to the former. One particularly important duty is for him to monitor his expert assessors: to know their strengths and weaknesses; to recognize their inevitable personal biases; and to satisfy himself that they are being fair and accurate. Such scrutiny applies just as much to applications for research grants and it should ensure that the type of occurrence cited by Dr. Horrobin occurs only rarely. Inevitably mistakes are made, and Sir Hans Krebs has recently related how his account of the citric acid cycle was rejected by the first journal to which he submitted it. ${ }^{1}$ Need it be added, however, that good work is rejected more often because the referee misjudges its importance than because he is malicious.

In small countries, where the number of experts in any subject is small there may be personal difficulties, and here the editor may need advice from experts overseas. Similarly, even in a large country, the seeker after research grants may have only a small choice of bodies to apply to, and may find that the same experts advise several of these. Indeed, the problem with allocating grants is potentially more serious than with articles submitted for publication: there are always other journals to turn to, whereas rejection of an application for a grant may stop a particular piece of research from ever being carried out.

Despite these difficulties is there any alternative to the present referee-based system? Adjudicating on papers and applications is often a time-consuming and thankless task, which rarely carries any prestige or payment, yet the quality of much scientific work depends on it. Should referees be made to sign the reports sent to the author, as Jones ${ }^{1}$ has suggested? The answer must surely be no, since few referees would be prepared to wound with the unvarnished truth, and the practice would almost certainly lead to personal conflicts between them and the authors, or the heads of their departments.

Should papers be sent to referees shorn of their list of 
authors? This, again, is scarcely practicable. The referee may spend much of his time trying to decide on the authorship, which anyway is often evident since earlier work from the team is cited. To some extent the credence placed on results depends on the scientific reputation of the research team responsible for it. It is naive and unrealistic to expect work to be assessed solely at its face value.

The solution to most of these problems lies in discussing the principles of decision-making in the open, for this is in the best interests of all concerned and the advancement of research and knowledge. That there have been so few reports like Dr. Horrobin's is surely a tribute to the generally fair working of the system: the facts contained in his stimulating article should prompt those responsible for running it to ensure that it continues in this way.

1 Jones, R. New Scientist, 21st March, p. 758.

2 Council of Biological Editors. Discussions of Editorial Policy by the CBE Committee on Editorial Policy, New York, 1972. See also CBE Style Manual, 3rd edition. New York, Council of Biological Editors, 1972.

\section{Drugs for Gastric Ulceration}

For many years attempts to improve the treatment of gastric ulceration concentrated upon the assessment of established clinical remedies. Early in the last decade, however, the accent switched to a new generation of drugs which shared a single feature in common, namely their lack of effect upon gastric acid secretory potential.

The first and most extensively tested drug was carbenoxolone sodium, a synthetic derivative of glycyrrhetinic acid produced from crude liquorice extract. It proved extremely effective in accelerating ulcer healing, but it also suffered from frequent undesirable side effects of salt and water retention, and, occasionally, hypokalaemia and raised blood pressure, and these limited its clinical usefulness. ${ }^{12}$ Both the side effects and the healing action proved to be dose related; and, curiously, both could be blocked by the administration of an aldosterone antagonist, spironolactone. ${ }^{3}$ Clinical trials continue but some of these seem more to be sad commentaries upon the disparate attitudes of national drug agencies than to be clinically necessary. ${ }^{45}$

The undoubted success of carbenoxolone and its undoubted drawbacks have led to a search for analogues with equivalent healing capacity but less side effects. One carefully tested preparation has been deglycyrrhizinated liquorice. This is liquorice from which most of the glycyrrhizinic acid (from which carbenoxolone is ultimately made) has been removed. Clinical assessments have run through the familiar range from early evidence of an equivalent effect to carbenoxolone ${ }^{6}$ to later results suggesting an effect definitely superior to placebo but marginally inferior to carbenoxolone ${ }^{78}$ and finally to a carefully conducted Scandinavian trial which showed no demonstrable effect at all. ${ }^{9}$ In these circumstances an unequivocal assessment is impossible, and though it seems likely that the drug has an anti-ulcer effect it is hard to be certain how great this is. Indeed one cannot be sure what the relative contributions may be of any new anti-ulcer principle or of residues of carbenoxolone-like material.

Among other drugs tested a carbenoxolone analogue without any effect on salt and water metabolism proved to have substantially less ulcer healing activity than carbenoxolone; $;^{10}$ while since ulcers are usually less common in women, and stilboestrol had been claimed to be effective in duodenal ulcer, it was tried in gastric ulceration but without any convincing result. ${ }^{11}$ Gefanate, a synthetic squalene derivative, has been used extensively outside the United Kingdom as an anti-ulcer drug, but a recent large clinical trial conducted here has failed to confirm previous impressions of its value though side effects were notably few. ${ }^{12}$ Bismuthbased compounds have long been claimed to have important ulcer healing effects, and a chelated bismuth preparation has been said to be of value in ulcer treatment, but the evidence to support its use could be more convincing.

Gastric ulceration is known to be associated with biliary reflux into the stomach, and the combination of acid and bile is known to promote back diffusion of acid into the gastric mucosa. This process could well predispose to gastric damage and ulceration, but a bile acid binding resin, cholestyramine, has failed to help ulcer healing. ${ }^{13}$

Two ranges of compounds which deserve more attention are antipepsins and antisecretory drugs. A single trial conducted in the U.S.A. suggested a marked effect upon ulcer healing rates, and clearly needs further examination, ${ }^{14}$ while anticholinergic drugs - of doubtful value in duodenal ulceration-may be worthy of further attention in gastric ulceration. ${ }^{15}$

Where is the clinician to turn when faced with this variety of drugs? Where regular follow up is possible and the patient has no serious degree of cardiorespiratory or renal disease then carbenoxolone seems still to be the drug of choice. However, in patients with associated disease or the very elderly (who seem especially prone to carbenoxolone side effects) either its dose must be very much reduced or another drug prescribed. In this situation deglycyrrhizinated liquorice seems the most logical choice as free of side effects and probably reasonably effective; but the virtues of established simple treatment (bed rest and stopping smoking) must not be forgotten.

\footnotetext{
Doll, R., Hill, I. D., Hutton, C., and Underwood, D. J., Lancet, 1962, 2, 793.

2 Horwich, L., and Galloway, R., British Medical fournal, 1965, 2, 1274.

3 Doll, R., Langman, M. J. S., and Shawdon, H. H., Gut, 1968, 9, 42.

Wolf, J., American fournal of Gastroenterology, 1973, 60, 23.

Rudick, J., American fournal of Gastroenterology, 1973, 60, 81.

Turpie, A. G. G., Runcie, J., and Thomson, T. J., Gut, 1969, 10, 299.

Wilson, J. A. C., British fournal of Clinical Practice, 1972, 26, 563.

Montgomery, R. D., and Cookson, J. B., Clinical Trials fournal, 1973, 9, 33.

Engqvist, A., von Feilitzen, F., Pyk, E., and Reichard, H., Gut, 1973, 14, 711 .

10 Fraser, P. M., Doll, R., Langman, M. J. S., Misiewicz, J. J., and Shawdpn, H. H., Gut, 1972, 13, 459 .

11 Doll, R., Langman, M. J. S., and Shawdon, H. H., Gut, 1968, 9, 46.

2 Langman, M. J. S., Knapp, D. R., and Wakley, E. J., British Medical Fournal, 1973, 3, 84.

13 Black, R. B., Rhodes, J., Davies, G. T., Gravelle, H., and Sweetnam, P., Gastroenterology, 1971, 61, 821.

Zimmon, D. S., Miller, G., Cox, G., and Tesler, M. A., Gastroenterology, 1969, 56, 19.

15 Baume, P. E., Hunt, J. H., and Piper, D. W., Gastroenterology, 1972, 63, 399.
}

\section{What is Community Medicine?}

Many doctors outside the newly formed specialty of community medicine are still far from certain what is meant by the term: what are the 2,000 or so Fellows and members of the newlyformed Faculty of Community Medicine going to do? At first sight it seems difficult to see what common ground exists for medical administrators, public health doctors, and academics from departments of social medicine. Too often those 